\title{
La Problemática Actual de la Monarquía Española: entre el Debate Funcional y la DiscriminaCión en la SUCESIÓN
}

\section{The Current Problematic of the Spanish Monarchy: between the Functional Debate and Discrimination In the Succession}

\begin{abstract}
1 Introducción. 2 La Monarquía y el contexto Constitucional Español de 1978. 3 El artículo 57 de la constitución en cuanto a la sucesión en el trono. 3.1 Confrontación del artículo 57 con los artículos 1.1 y 14.3 .2 La reforma del artículo 57 o la inclusión de una disposición transitoria. 4 Planteamiento y proceso de reforma de la constitución por el artículo 168. 5 Referéndum y ratificación de la constitución. 5.1 ¿Y si el proceso de reforma es el fundamento de una consulta popular del debate sobre la monarquía? 6 Conclusiones. Referencias.
\end{abstract}

\section{RESUMEN}

Objetivo: Analizar la desigualdad de género del artículo 57 de la Constitución por el que se regula el orden de sucesión al trono, y su posible reforma constitucional a través del procedimiento agravado del artículo 168 de la Constitución española.

\footnotetext{
"Profesor en la Universidad Rey Juan Carlos y en la Universidad Complutense de Madrid. Licenciado en Derecho por la Universidad Complutense de Madrid, y Doctor en Derecho por la Universidad de Alcalá de Henares, con el que obtuvo la mención Cum Laude. En el ejercicio de su actividad docente se ha especializado en Derecho Público siendo profesor universitario y profesor de máster desde hace varios años en las universidades españolas. Autor de diversos artículos publicados en revistas de impacto, libros y capítulos de libro y colaboraciones. Ha participado como conferenciante en cursos y seminarios en España en entidades españolas y extranjeras, siendo sus líneas de investigación la historia jurídica constitucional de España y el estudio de las instituciones del Estado. Universidad Rey Juan Carlos de Madrid, Espanha. E-mail: <d.martinezcristobal@gmail.com>.https://orcid.org/00000001-9754-5688
} 
Metodología: Se partirá de una reflexión sociológica y constitucional en base a la legalidad de una consulta popular acerca de la viabilidad de la Monarquía española a partir de una reforma constitucional para adecuarla a la realidad actual.

Resultados: Queda demostrado el importante papel que juega la Corona española en el orden constitucional español, y la gran protección que goza para evitar la desestabilización como Jefatura del Estado. A pesar de ello, es necesaria la adaptación de la igualdad de género en todos los ámbitos constitucionales, debido principalmente a que la futura reina de España es la Princesa Leonor.

Contribución: El debate político sobre la Monarquía española comenzó en el mismo momento que se aprobó la Constitución española de 1978, pero hoy más que nunca ha resurgido esa discusión a causa de su obligada adecuación a la realidad social en relación con el principio de igualdad del artículo $1.1 \mathrm{y}$ el derecho de igualdad reflejado en el artículo 14 , que podría desembocar en una consulta a la ciudadanía para decidir entre monarquía y república.

Palabras clave: Monarquía. Sucesión. Referéndum. Inconstitucionalidad. Reforma constitucional.

\section{ABSTRACT}

Objective: To analyze the gender inequality of article 57 of the Constitution regulating the order of succession to the throne, and its possible constitutional reform through the aggravated Procedure of the article 168 of the Spanish Constitution.

Methodology: It will be based on a sociological and constitutional reflection based on the legality of a popular consultation on the viability of the Spanish Monarchy from a constitutional reform to adapt it to the current reality.

Results: The important role played by the Spanish Crown in the Spanish constitutional order, and the great protection it enjoys to prevent destabilization as Head of State, is demonstrated. Despite this, the adaptation of gender equality is necessary in all constitutional areas, mainly because the future queen of Spain is Princess Leonor.

Contribution: The political debate on the Spanish Monarchy began at the same time as the Spanish Constitution of 1978 was adopted, but today more than ever this discussion has resurfaced because of its obligatory adaptation to social reality in relation to the principle of equality of article 1.1 and the right of equality reflected in article 14, which could lead to a consultation of citizens to decide between monarchy and republic.

Keywords: Monarchy. Succession. Referendum. Unconstitutionality. Constitutional Reform. 
La problemática actual de la Monarquía Española: entre el debate funcional y la discriminación en la sucesión

\section{INTRODUCCIÓN}

La Monarquía parlamentaria es la forma de gobierno en España desde 1978 a través del artículo 1.3 de la Constitución ${ }^{1}$, reconociendo el papel desempeñado por el rey Juan Carlos I en la Transición política, dotando a la monarquía de un poder configurador en la estructura del Estado español pero prescindiendo de la potestas y manteniendo la auctoritas, ya que carece de cualquier poder de decisión política, pues sus funciones deben ser consideradas siempre como actos debidos y nunca como actos discrecionales (ÁLVAREZ CONDE; TUR AUSINA, 2018, p. 595).

En palabras de Luis López Guerra el Parlamento, Gobierno y jueces se configuran como auténticos centros de poder, mientras que el Rey se convierte en una figura casi honorífica, en la que reina pero no gobierna (OLIVER ARAUJO; CALAFELL FERRÁ, 2017, p. 183); y también constituye el último estadio de la evolución histórica de las Monarquías, como consecuencia de la introducción y desarrollo de los principios democráticos (ÁLVAREZ CONDE; TUR AUSINA, 2018, p. 589).

Debido a la peculiaridad de la Transición española se hizo indiscutible el simbolismo de la Corona de la dictadura a la democracia, pero en los últimos tiempos se ha intensificado el debate en España sobre si la monarquía ya ha cumplido su papel en la historia reciente del país y debería dar paso a una nueva etapa caracterizada por el comienzo de una nueva república, en el que algunos partidos políticos apoyan un cambio de rumbo en la política española que lleve a su instauración y que varios sectores de la ciudadanía apoyarían o no se opondrían a dicho cambio.

Una parte de la población española no se siente representada por la monarquía al sentir como una imposición tradicionalmente histórica que se encuentra actualmente obsoleta respecto a la evolución de la sociedad. Las generaciones nacidas en el siglo XXI ven muy lejos la Transición y no existe ningún vínculo que permita sentirse parte de ella, sintiéndola ajena a su mentalidad e inquietudes, ya que entienden que la Corona como Jefatura del Estado nunca se ha sometido su continuidad a votación, e incluso se ha visto salpicada por temas relativos a la corrupción económica, con lo que el descontento social se ha visto incrementado.

Por tanto, la Jefatura de Estado española adolece de dos problemas fundamentales, como son un alejamiento de la sociedad y la crítica a una desigualdad en el orden de sucesión, que se enfrentaría a la igualdad constitucional. Ante la polarización de la ciudadanía, cabría preguntarse si resultaría factible exigir una consulta

\footnotetext{
${ }^{1}$ La Constitución española de 1978 en su artículo 1.3 establece que la forma política del Estado español es la Monarquía parlamentaria.
} 
popular para que los españoles votasen sobre la permanencia de la monarquía mediante el artículo 92.1 $1^{2}$ de la Constitución en uso del plebiscito consultivo.

La duda que viene a la mente sería si la monarquía debe adaptarse rigurosamente a los fundamentos democráticos que constituyeron el contexto político de 1978, tanto en la igualdad en el terreno de la sucesión como el sometimiento a votación del futuro de la Jefatura del Estado. La duda que se resolverá en este trabajo resalta si el artículo 57 de la Constitución vulnera de forma directa lo regulado en el artículo 1.1, el cual propugna la igualdad como valor fundamental y superior del ordenamiento jurídico, al mismo tiempo que el artículo 14 consagra el derecho fundamental de igualdad ante la ley, entre la que se encuentra la discriminación por razón de sexo ${ }^{3}$.

¿Es necesario requerir esta vía de participación popular para que la ciudadanía manifieste un deseo de actualización de la Corona o incluso su preferencia acerca de un cambio entre monarquía y república? ¿Dicho referéndum consultivo podría llevarse a cabo a través del artículo 92 y que provocase la reforma constitucional prevista en el artículo 168 ?

\section{LA MONARQUÍA Y EL CONTEXTO CONSTITUCIONAL ESPAÑOL DE 1978}

El VII de los Principios del Movimiento Nacional establecía que la forma política del Estado sería la Monarquía tradicional, católica, social y representativa, pero ni la Ley de Sucesión a la Jefatura del Estado de 26 de julio de 1947, modificada por la Ley Orgánica del Estado de 10 de enero de 1967 concretaba qué persona podría ser designada con base a dicha elección, salvo los requisitos exigidos al futuro titular de la Corona en la que abarcaba como afirmó Fernández-Carvajal a "instituir un amplísimo jus ad officium a favor de todo varón mayor de treinta años, que además fuera español, católico y de estirpe regia”. Hay que destacar la importancia que tiene la sucesión en los regímenes autoritarios donde cobra mayor importancia que en otros, ya que depende de la figura irrepetible de su fundador y la vinculación del mismo modo en un futuro a quien sea el sucesor (FERRANDO BADÍA, 1980, p. 8).

El 22 de julio de 1969 Juan Carlos de Borbón fue nombrado sucesor de Francisco Franco en la Jefatura de Estado. Con su elección como Príncipe de España, y la referencia a la estirpe regia en el artículo octavo de la Ley de Sucesión que suponía un concepto más amplio que el de dinastía, se pretendía la instauración y no restauración de una monarquía. La legitimidad dinástica en España correspondía a don Juan de Borbón como heredero de Alfonso XIII, aunque las desavenencias con Francisco Franco

\footnotetext{
2 Está establecido que las decisiones políticas de especial trascendencia podrán ser sometidas a referéndum consultivo de todos los ciudadanos.

${ }^{3}$ STC 216/1991, 14 de noviembre, FJ 6.
}

157 • R. Opin. Jur., Fortaleza, ano 19, n. 31, p.154-174, maio/ago. 2021 
La problemática actual de la Monarquía Española: entre el debate funcional y la discriminación en la sucesión

provocaron que eligiese a su hijo, que hasta la renuncia del padre como heredero al trono en 1977 no obtuvo el pleno derecho sobre ella.

Dos días después de la muerte de Franco, el 22 de noviembre de 1975 Juan Carlos de Borbón fue proclamado rey de España por las Cortes Españolas. A pesar de que la opinión pública no era monárquica, ésta se instauraría ya que el ejército, la jerarquía eclesiástica del Opus Dei y los organismos financieros y patronales estaban a favor de ella. Esto le permitió adquirir una legitimidad democrática que no había sido nunca respaldada y que se ratificó posteriormente con la aprobación de la Constitución española de 1978 (LÓPEZ-ARANGUREN JIMÉNEZ, 1974, p. 14).

Pese a haber jurado fidelidad a las Leyes Fundamentales del Reino y a los Principios del Movimiento Nacional, alentó la Ley 1/1977, de 4 de enero, para la Reforma Política ${ }^{4}$ votada y aprobada por el Congreso de los Diputados el 18 de noviembre de 1976 y ratificada en referéndum el 15 de diciembre con un apoyo del 94,14\%, iniciándose la Transición Española.

Cualquier otra idea de gobierno que no fuese un directorio militar o una monarquía estaba amenazado por probables alteraciones de orden público que proporcionarían al ejército la ocasión de intervenir y alzarse con el poder (LÓPEZARANGUREN JIMÉNEZ, 1974, p. 15). La cesión de competencias atribuidas por el nuevo rey y la adopción de un programa político democrático y social le permitió seducir a los monárquicos dinásticos tradicionalistas que defendían la figura regia del Conde de Barcelona.

Tras las elecciones generales del 15 de junio de 1977 se conformaron las Cortes constituyentes para propiciar la redacción de la nueva Constitución que finalizarían el 2 de enero de 1979. Uno de los temas más controvertidos y de mayor discusión fue el Título II referente a la Corona, ya que Felipe de Borbón había sido proclamado Príncipe de Asturias ${ }^{5}$ en Covadonga el 1 de noviembre de 1977.

Este acto supuso un debate jurídico y político por el respeto a la Comisión Constitucional del Congreso de los Diputados que ya había elegido la Ponencia constitucional para la redacción del anteproyecto de Constitución ${ }^{6}$ y que estaba iniciando su trabajo, y por el que el senador Manuel Villar Arregui manifestó que mantener la disposición del artículo 57.1 supondría una vejación a todas las mujeres

\footnotetext{
4 Suponía atribuir al Rey poderes más amplios que los contemplados en las propias Leyes Fundamentales, siendo más cercana a una Monarquía presidencialista.

${ }^{5}$ Acto por el que se restableció la tradición creada por Juan I en 1388 para los herederos del Trono de Castilla y que se mantuvo hasta 1907 con Alfonso de Borbón.

${ }^{6}$ Los famosos siete padres de la Constitución española de 1978 que fueron elegidos en una Ponencia Constitucional a través de la Comisión de Asuntos Constitucionales y Libertades Públicas en el Congreso de los Diputados.
} 
españolas, desde el momento de reclamar valores constitucionales igualitarios, y que existiese una preferencia en la organización institucional.

Algunos políticos lo consideraron como un acto de carácter jurídico impreciso que con unas Cortes maniatadas bajo la vigilancia de sectores se sintieron impedidas de contradecir la expresa voluntad del Rey (OLIVER ARAUJO, 2002, p. 20). Incluso Antonio Torres del Moral, señaló que tras el nombramiento como Príncipe de Felipe de Borbón por encima de su hermana Elena las Cortes Constituyentes deberían haber declarado heredero al actual rey y concretar un orden de sucesión futuro sin distinción de sexo, modificando ese precepto del artículo 57.1.

El 2 de junio de 2014 el rey Juan Carlos I manifestó su renuncia al trono de España, y la abdicación en su hijo Felipe que asumió el cargo con el nombre de Felipe VI.

\section{EL ARTÍCULO 57 DE LA CONSTITUCIÓN EN CUANTO A LA SUCESIÓN EN EL TRONO}

La Constitución regula de forma automática la sucesión en el trono de forma que en ningún supuesto la Corona pueda quedar vacante. De este modo, la transmisión de la Corona se efectúa ope legis en el seno de la familia real cuyos miembros ostentan el derecho a ocupar el trono en caso de vacante, según el orden al objeto establecido (PÉREZ SERRANO, 1984, p. 75).

El artículo 57 de la Constitución establece el orden de sucesión en la monarquía española, y en el primer precepto dispone que la Corona de España será heredada por los sucesores de Juan Carlos I como legítimo heredero de la dinastía histórica, siguiendo el orden regular de primogenitura y representación, a lo que Luis Sánchez Agesta se refiere en cuanto a la preferencia del primogénito y sus descendientes, de padres a hijos y nietos y así de forma sucesiva, siempre dando preferencia a los hermanos y sobrinos, por razón de línea. De esta manera las mujeres tienen acceso al trono siempre que no tengan hermanos varones y la preferencia de línea con derechos de representación significa que los nietos anteceden en caso de fallecimiento a sus padres y tíos (SÁNCHEZ AGESTA, 1984, p. 230).

Es indispensable la intervención de las Cortes Generales en el orden de sucesión de la Corona estipulado en el artículo 57.3 y 5 de la Constitución para dar solución a la problemática referente a la abdicación, renuncia u otra cuestión vinculada que se pudiera producir mediante la publicación de una ley orgánica, además de proveer la sucesión cuando se hubiesen extinguido todos los grados de consanguinidad estipulados. 
La problemática actual de la Monarquía Española: entre el debate funcional y la discriminación en la sucesión

La sucesión en la Corona española regulada mediante el artículo 57, estipula que dentro del mismo grado siempre tendrá preferencia el varón sobre la mujer, lo cual vulnera la igualdad de pleno derecho preceptuada en la Constitución tanto en el artículo 1.1 que propugna como valores superiores de nuestro ordenamiento jurídico la libertad, la justicia, la igualdad y el pluralismo político, como en el artículo 14 en el que se establece que todos los españoles son iguales ante la ley, sin que pueda existir algún tipo de discriminación por motivos de nacimiento, raza, sexo, religión, opinión o cualquier otra condición o circunstancia personal o social. Así pues,

El precepto constitucional que prohíbe toda discriminación por razón de sexo es de aplicación directa e inmediata desde la entrada en vigor de la Constitución. Su adecuada interpretación exige, sin embargo, la integración sistemática del mismo con otros preceptos de la Ley fundamental, pues así lo precisa la unidad de ésta (ESPAÑA, 1991, online). ${ }^{7}$

Por ello, al introducir la preferencia del hombre sobre la mujer como disposición en la estructura sucesoria a la Corona de España en el artículo 57 de la Constitución, ¿existe una "inconstitucionalidad constitucional" dentro de la Carta Magna al discriminar y limitar el acceso de las mujeres al trono únicamente en caso de que no existan hermanos varones? La Constitución a pesar de defender la igualdad de género sigue manteniendo una discriminación trascendental que ya fue objeto de debate en el Anteproyecto de la Constitución ${ }^{8}$ que aunque no creó controversias en el Congreso de los Diputados sí existieron en el Senado cuando se planteó suprimir la preferencia del varón en la sucesión, dando la razón a una actualización por el que

el artículo 14 de la Constitución no puede ser interpretado ni por los tiempos pasados ni por el Derecho preconstitucional. Es el artículo 14 quien debe ser la norma para juzgar de lo que se practicó en los tiempos pasados y de lo que establecía el Derecho preconstitucional, que sólo sigue válido y vigente en cuanto que no se oponga a la Constitución (GARCIA TORRES, 1990, p. 273).

En tanto que los arts. 1.1 y 14 de la Constitución son considerados pilares básicos del sistema democrático, el Tribunal Constitucional en su Sentencia 126/1997, de 3 de julio, afirmó en su Fundamento Jurídico 7 que "la conformidad con la Constitución del orden regular de sucesión en la Corona no puede suscitar duda alguna, por haberlo establecido así el constituyente." (ESPAÑA, 1997, online). Se consagró como código sucesorio el fundamento de masculinidad que se aplica por analogía, ya que legalmente se establece en las Partidas $(2,15,2)$ que regulan la sucesión en la Corona.

\footnotetext{
${ }^{7}$ STC 216/1991, 14 de noviembre, FJ $5^{\circ}$.

${ }^{8}$ Anteproyecto de la Constitución, Boletín Oficial de las Cortes no 44, 5 de enero de 1978. 
En respuesta al deber de los órganos judiciales de eliminar situaciones discriminatorias de origen preconstitucional, el Tribunal declaró que "el respeto a la Constitución exige, sin duda, que se hagan desaparecer situaciones jurídicas nacidas de actos jurídicos contrarios al orden constitucional”, estableciendo que la Constitución prohíbe toda discriminación por condición social o personal que, en ningún caso, justifican diferencias de trato 9 .

\subsection{CONFRONTACIÓN DEL ARTÍCULO 57 CON LOS ARTÍCULOS 1.1 Y 14}

En el Informe de 2006 del Consejo de Estado sobre modificaciones de la Constitución española realizado a solicitud del Gobierno se señaló que la preferencia del varón sobre la mujer

no nace de ninguna clase de contradicción jurídica que sea preciso salvar entre ella y la regla de no discriminación por razón de sexo que enuncia el artículo 14, ya que ambas reglas han sido establecidas por el mismo poder constituyente, una con carácter general y otra con carácter singular, limitada ésta a un único objetivo: acomodar la sucesión en el trono al orden histórico (ESPAÑA, 2006, p. 14-15).

por lo tanto, el poder constituyente delimitó como excepción al precepto general de la igualdad el artículo 57.1 en cuanto a la preferencia por razón de sexo. Añadió que los artículos 14 y 57.1 tienen ámbitos de aplicación diferentes en la Constitución, por lo que no interfirieren sus preceptos.

Una parte de la doctrina, partiendo de la contradicción existente en la Norma Fundamental, declara que esta cuestión podría resolverse sin la necesidad de una modificación dando preferencia a los preceptos más importantes o esenciales frente a los que se consideran particulares dirigidos a un asunto en concreto.

A pesar de todo, la necesidad de una reforma del artículo 57 deriva del lento desgaste que soporta en la percepción social todo tipo de subordinación de la mujer, y un auge del feminismo para la igualdad absoluta incluyendo contenidos tan singulares como la monarquía, acomodando la Constitución a la realidad social de nuestros tiempos, pero tras el nacimiento de la infanta Sofía en 2007 el aprieto de una reforma del artículo 57 se estancó ya que no se planteó la tesitura de la pérdida de privilegios de la princesa Leonor.

Los preceptos del artículo 57 son normas singulares que organizan la sucesión de los designados dentro de la monarquía española y que no altera su condición de normas constitucionales positivas susceptibles de modificación, y no simples alteraciones de normas de carácter histórico que se aplican en el tiempo de forma indistinta ya que fueron incorporadas por el poder constituyente con una función especial.

${ }^{9}$ STC 91/1986, 2 de julio, FJ $1^{\circ}$.

161 • R. Opin. Jur., Fortaleza, ano 19, n. 31, p.154-174, maio/ago. 2021 
La problemática actual de la Monarquía Española: entre el debate funcional y la discriminación en la sucesión

Otra parte de la doctrina aboga por una reforma real de la Carta Magna para plasmar la plena igualdad en la sucesión de la Corona con arreglo a lo dispuesto en el Título X de la Constitución, aunque no hubo en su momento un consenso claro acerca de la retroactividad o no de la modificación. En este caso Francisco Rubio Llorente manifestó al conocer el primer embarazo de la entonces princesa Letizia, que las modificaciones constitucionales realizadas podrían aplicarse de forma retroactiva al primogénito de los príncipes "aunque fuera niña y naciese antes de que la reforma se efectuase". En cambio, Jorge de Esteban afirmó que "no existe ese carácter retroactivo. Si Letizia tuviese un hijo sin que la Constitución se haya reformado, sería el sucesor. De lo contrario, también la infanta Elena podría reclamar sus derechos sobre Felipe." (QUÍLEZ, 2020, online).

El proceso de reforma es un complejo mecanismo ya que cualquier intento de modificación de la Constitución que afecte al Título preliminar, al Capítulo Segundo, Sección primera del Título I, o al Título II debe hacerse mediante el procedimiento agravado del artículo $168^{10}$, lo que implica que tiene que ser aprobada por una mayoría de dos tercios en el Congreso y en el Senado, para posteriormente disolver ambas Cámaras y proceder a la convocatoria de elecciones y en última instancia ser sometido a referéndum.

\subsection{LA REFORMA DEL ARTÍCULO 57 O LA INCLUSIÓN DE UNA DISPOSICIÓN TRANSITORIA}

La actualización de la igualdad en la Corona podría realizarse mediante la reforma del artículo en cuestión adaptándolo a la realidad social mediante un precepto de carácter sustantivo que eliminaría la preferencia del varón en la sucesión, y otro de carácter transitorio que aseguraría la posición del actual monarca como rey de España, sin la posible aplicación retroactiva en favor de su hermana Elena.

El Consejo de Estado en el informe sobre modificaciones de la Constitución española en 2006 propuso la reforma únicamente del artículo 57.1 para la eliminación de la preferencia surtiendo efectos permanentes a partir del momento de su aprobación aunque fuese de naturaleza ácrona, y sin introducir una disposición transitoria ya que su redacción partiría en dos mandatos diferentes el contenido de un dictamen extraordinario, pudiendo dar lugar a delicadas controversias jurídicas sobre cuál sería el régimen jurídico aplicable en caso de una posible reforma de la disposición.

${ }^{10}$ El artículo 167 se corresponde con el procedimiento de reforma ordinario, usado para reformar parcialmente preceptos no esenciales de la Constitución. 
Por ello, en la modificación propuesta para el artículo 57.1 se suprimió la frase "en el mismo grado, el varón a la mujer" como asunto crucial de la reforma planteándose como

La Corona de España es hereditaria en los sucesores de S. M. Don Juan Carlos I de Borbón, legítimo heredero de la dinastía histórica. La sucesión en el trono corresponde a su hijo, el Príncipe heredero Don Felipe de Borbón, y después seguirá el orden regular de primogenitura y representación, siendo preferida siempre la línea anterior a las posteriores; en la misma línea, el grado más próximo al más remoto; y en el mismo grado, la persona de más edad a la de menos (ESPANÃ, 2006, online). ${ }^{11}$

Otras de las soluciones planteadas, aunque de gran calado reformista, es el uso de un lenguaje inclusivo ${ }^{12}$ en el cual no se excluyese a ninguno de los dos sexos, argumentando la incapacidad actual de un lenguaje únicamente masculino con el que se pueda abarcar todas las expresiones que afectan de manera detallada al género en todo el texto constitucional. Históricamente en las Constituciones españolas nunca han existido distinciones entre rey y reina en función de si el titular de la Corona era varón o mujer, incluso cuando el monarca reinante fue Isabel $\mathrm{II}^{13}$.

Algunos expertos en Derecho Constitucional han acudido al derecho comparado para buscar modelos de referencia para aludir a la reina o a la heredera del trono como la Constitución noruega ${ }^{14}$, la Ley de Sucesión de Suecia ${ }^{15}$ en las que menciona a ambas.

También el uso del masculino como genérico, considerando que se sobreentienden las referencias que se hacen al rey o al heredero se hacen igualmente a la reina o a la heredera utilizado en la Constitución belga y la Constitución de los Países Bajos.

En el caso del Consejo de Estado se abogó por el uso del lenguaje femenino introduciendo una cláusula genérica donde se advirtiese que las palabras usadas en la forma masculina hiciesen referencia en aras de la economía lingüística a ambos géneros indistintamente, y se consideró suficiente que únicamente se reformasen con sentido igualitario los términos que cuando hiciesen referencias al rey o príncipe, siendo

\footnotetext{
${ }^{11}$ Informe de 2006 del Consejo de Estado sobre modificaciones de la Constitución española.

${ }^{12}$ Informe de la Real Academia Española sobre el uso del lenguaje inclusivo en la Constitución española, elaborado a petición de la vicepresidenta del Gobierno en enero de 2020.

${ }^{13}$ Es de resaltar la alusión en la Constitución de 1812, en la que se diferencia en los artículos 202 y “a los hijos e hijas del Rey" y "los hijos e hijas del Príncipe de Asturias", además del Estatuto Real de 1834 que en el artículo 28 hacía mención "al Príncipe o Princesa".

${ }^{14}$ Consistiría en mencionar a la reina junto al rey y a la heredera junto al heredero del trono en todas aquellas ocasiones que hay que referirse a una y otro. También al referirse al rey y al heredero añadiendo un precepto que determine y esclarezca que las referencias hechas a alguno de estos se deben entender hechas a la reina o heredera respectivamente reflejado en su artículo 3.

${ }^{15}$ Establece que será el jefe de Estado del reino el rey o la reina que ocupe el trono. Y refiriéndose en el artículo 2 que las disposiciones relativas al rey se refieren también a la reina si la reina es el jefe del Estado.
}

163 R. Opin. Jur., Fortaleza, ano 19, n. 31, p.154-174, maio/ago. 2021 
La problemática actual de la Monarquía Española: entre el debate funcional y la discriminación en la sucesión

extensivos por ende a la reina o princesa ${ }^{16}$. Aunque esto provocaría un rechazo a las actuales tendencias que respaldan el uso de un lenguaje no sexista, sacrificando la justicia por la economía, al aceptar como correcto el uso del masculino de forma general y no sería necesaria la cláusula de referencia que hace el legislador entendiendo que es injusta la ocultación del género (BALAGUER CALLEJÓN, 2006, p. 398) y aceptando una discriminación en cuanto al papel de las mujeres en la Corona.

\section{PLANTEAMIENTO Y PROCESO DE REFORMA DE LA CONSTITUCIÓN POR EL ARTÍCULO 168}

Una vez presentada la iniciativa de reforma constitucional en las Cortes, comienza su estudio de calificación en la Mesa, encargándose de comprobar el cumplimiento de los requisitos de legitimación, diferentes en cada tipo de iniciativa, así como de tiempo y forma, debiendo quedar debidamente diferenciadas las partes o preceptos constitucionales a los que la reforma va a afectar para la consideración de trámite del procedimiento ordinario o agravado, las llamadas por Schmitt "decisiones constitucionales fundamentales" (MÁRQUEZ, 2008, p. 181).

El proceso de reforma agravado que establece la Constitución española permite que las proposiciones sean objeto de debate en la primera legislatura según lo establecido en el artículo 147 del Reglamento del Congreso y se divide en tres bloques diferenciados (ÁLVAREZ CONDE; TUR AUSINA, 2018, p. 123), primeramente por la aprobación de la propuesta de modificación por las Cortes y la celebración de elecciones, tras lo cual la reforma sería planteada y votada por cada una de las nuevas Cámaras y posteriormente ser ratificada por la ciudadanía en caso de haber sido aprobada.

El primer paso durante la aprobación de la decisión de reforma por el Congreso por una mayoría de dos tercios, se traslada la votación al Senado en el que no existe la posibilidad de desacuerdo por lo que dicha mayoría no puede ser disminuida ${ }^{17}$, ya que es imprescindible para asegurar el acuerdo de las diferentes propuestas necesarias para la búsqueda y resolución de un consenso constitucional a partir del pacto de los partidos políticos que deriva en el principio de la revisión, con lo cual parece indicar que

\footnotetext{
${ }^{16}$ Se propuso añadir al artículo 57 un sexto apartado en el que se aclararía que las referencias al rey y al príncipe que hace la Constitución se ampliarían indistintamente tanto al rey o a la reina como al príncipe o princesa, en cada momento concreto.

${ }^{17}$ En caso de no existir acuerdo entre las Cámaras, el procedimiento habría llegado a su fin e implicaría el fracaso de la iniciativa de la reforma, a menos que reglamentariamente así se establezca y salvo un criterio de interpretación analógico relacionado con lo establecido en el art. 167.
} 
únicamente se trata de una decisión sobre la reforma constitucional y no de una elaboración del Proyecto de la reforma ${ }^{18}$.

Lo concerniente a la regulación que contiene el mencionado artículo permite un claro margen a la interpretación, así como a la exigencia de un desarrollo, lo cual hace surgir numerosas cuestiones al respecto, no resultando ser un artículo debidamente redactado, lo que le resta la escasa eficacia que actualmente ostenta (MÁRQUEZ, 2008, p. 178).

Cuando el Senado recibe el principio de reforma, éste es elevado directamente al Pleno. Consecuentemente, no se acepta ninguna tramitación de enmiendas en relación al inicio de reforma en la Cámara Alta, pero esto no entra en contradicción con lo que anteriormente era defendido para el Congreso, sino que entraña una gran lógica con la regulación constitucional, la cual no regula la resolución de desacuerdos entre ellas en lo que respecta a la determinación sobre el motivo de la reforma. Por lo tanto, y con la salvedad de que el Senado pudiera recoger sus decisiones acerca de las diligencias sobre la reforma agravada, su papel aquí se limitaría a avalar o rectificar la resolución previamente aceptada en el Congreso.

Una vez aprobada por ambas Cámaras, el presidente del Congreso deberá comunicar al Gobierno la decisión, y la Constitución ordena la disolución inmediata de las Cortes y la convocatoria de elecciones estableciéndose el procedimiento mediante un Real Decreto. Se ha considerado por la doctrina que las actuaciones de las Cámaras producidas el día de la aceptación del comienzo de reforma constitucional son válidas hasta que tenga efecto el Real Decreto para la disolución de las Cortes.

Las elecciones convocadas contienen una nota diferencial respecto al resto de elecciones generales, ya que las distintas candidaturas políticas que concurren muestran las distintas posiciones respecto al principio de reforma constitucional en curso, aunque los partidos políticos mayoritarios preservan un pacto inicial sobre la revisión a pesar de la existencia de diferentes matices y el momento electoral de cada una de las representaciones no se reducirá únicamente a centrarse en las reformas, sino más bien a programar la legislatura tras las elecciones.

Se cuestiona la naturaleza de las Cortes elegidas puesto que se conciben como Cortes constituyentes, cuya única misión es aprobar la reforma constitucional. En lo concerniente a la actuación de las nuevas Cortes, primeramente se tiene que ratificar la decisión adoptada por las Cortes anteriores. Una vez que las Cámaras han adoptado el acuerdo de ratificación, se pasa al estudio del contenido del proyecto de la reforma que se plantea, implicando la posibilidad de que se realicen enmiendas y debates. Serán las Cortes las que elaboren el proyecto de la reforma, puesto que las anteriores únicamente

\footnotetext{
${ }^{18}$ En el Reglamento del Congreso solo se contempla un debate a la totalidad en el Pleno.

165 • R. Opin. Jur., Fortaleza, ano 19, n. 31, p.154-174, maio/ago. 2021
} 
La problemática actual de la Monarquía Española: entre el debate funcional y la discriminación en la sucesión

aprobaron la reforma de la Constitución. La reforma deberá ser aprobada por las nuevas Cámaras elegidas, de nuevo por mayoría de dos tercios en cada una de ellas.

En el momento constituyente, la finalidad del procedimiento parlamentario es permitir la participación de los partidos políticos representados en las Cámaras para abordar de forma interrelacionada los distintos temas controvertidos e intentar conseguir el mayor consenso posible, incorporando en un pacto conjunto los acuerdos alcanzados. La particularidad de que los intereses políticos de cada partido no sean los mismos en relación a cada materia facilita la posibilidad de concierto. Por ello, es imperativo el desarrollo de un procedimiento previo de análisis y debate parlamentario, a través del que pueda manifestarse un acuerdo político propicio para la modificación con el objetivo de que la aprobación eventual del intento de reforma alcance la mayor unanimidad posible.

Las segundas Cortes estarían vinculadas a consecuencia de su futura actuación tras la disolución del poder constituyente en cuanto a la decisión de ratificación del proyecto aprobado en la legislatura originaria y en la confección y trasformación posterior de la Constitución. La función que el artículo 168 otorga a las nuevas Cámaras una vez que se ha ratificado la iniciativa de reforma, se basa en el procedimiento del estudio del nuevo proyecto constitucional, partiendo de la base que las nuevas Cortes deben elaborar un texto como borrador de proyecto o proposición de ley.

La cuestión de si el proyecto de reforma puede ser ampliado mediante tramitaciones de enmiendas previas a presentar el resultado provisional de reforma por las Cortes más allá del inicialmente previsto por las Cortes disueltas. La extralimitación en la reforma de las partes o artículos señalados en la iniciativa y la modificación de otros que no estuviesen contemplados, ocasionarían una falta de consideración al proceso establecido en el art. 168 de la Constitución, y aunque en teoría no existe ningún impedimento para ello, es indudable que dicha actuación tiene que estar condicionada por la ratificación de la decisión que han tenido que adoptar anteriormente. Parecería entendible en principio un periodo para la presentación de enmiendas en el Congreso, las cuales sirviesen de herramienta para mejorar el texto del artículo en cuestión, incorporar en la creación a los partidos políticos que están presentes en las Cortes.

La tramitación del texto de la reforma debe ser debatida y aprobada por el Pleno del Congreso de los Diputados por una mayoría de dos tercios, para posteriormente trasladar el texto al Senado debiendo alcanzar la misma mayoría cualificada para que la enmienda se entienda aprobada por las Cortes.

Una de las interpretaciones más controvertidas del artículo 168 procede de las posibles discrepancias de las Cámaras, ya que si no existe acuerdo entre ellas la reforma quedaría desechada. Sin embargo, podría suceder que el Senado aprobase de igual 
manera por supermayoría un proyecto modificado mediante enmiendas, al que se aprobó en el Congreso de los Diputados.

La duda surge una vez aprobada la reforma, ya que no está especificado si deben ser disueltas o por el contrario poder seguir actuando como Cortes ordinarias, tal y como se establecía en el artículo 125 de la Constitución española de 1931. Al parecer, la solución se interpreta en la segunda opción ya que se habría estipulado de manera taxativa en caso de una posterior disolución de las Cortes. Esto no impide, siempre y cuando se den los requisitos generales referentes a la disolución, que se dé la posibilidad de que se disuelvan por el presidente del Gobierno y se proceda a la elección de unas nuevas Cortes.

Solo si se consigue este consenso parlamentario se puede solicitar el aval de la ciudadanía, indispensable en la vía de reforma del artículo 168 y potestativo en la del artículo 167, tras lo cual el presidente del Gobierno es notificado por el presidente del Congreso para la preparación del referéndum, de carácter obligatorio y no facultativo que se prevé en el artículo 168.3. La exigencia de este referéndum no parece justificada, sobre todo si se piensa que la preferencia de las Cortes respecto del artículo 168.2 viene a ser una especie de referéndum sobre la necesidad y el contenido de la reforma.

El problema fundamental que se plantea en relación a la iniciativa de la reforma constitucional agravada es la estructura a adoptar, ya que tanto en los Reglamentos como en el mismo artículo 168 no se establece su disposición, por lo que se entiende que debe tratarse de un texto redactado, no necesariamente estructurado y que refleje el articulado o las partes del texto constitucional afectadas, ya que es preceptivo que las Cortes tengan un conocimiento pleno sobre el estudio de la reforma, determinando el objeto de la reforma que se trata y el fin que se pretende alcanzar.

La regulación de la reforma constitucional permite a los principales actores del proyecto de modificación constitucional, el Gobierno y el Parlamento, ostentar la facultad de propuesta de los diputados, senadores, grupos parlamentarios y Asambleas de las CCAA. La discriminación a la iniciativa popular ha tenido muchos detractores a lo largo de los años dado el inexistente uso de este mecanismo de reforma, aunque sí se ha planteado que alguno de los grandes partidos políticos pudiese haber utilizado la opción política de una iniciativa popular para afrontar el planteamiento de una reforma constitucional y por consiguiente poder atraer a una parte del electorado deseoso de la actualización de la Carta Magna a la realidad actual española.

Seguramente se podría afirmar con rotundidad que si en algún momento dicha iniciativa popular existiese, se podría plantear la reforma del artículo 57 de la Constitución dado el contexto social en el que nos encontramos inmersos actualmente abogándose por la modificación del citado precepto en aras de la igualdad de género. 
La problemática actual de la Monarquía Española: entre el debate funcional y la discriminación en la sucesión

\section{REFERÉNDUM Y RATIFICACIÓN DE LA CONSTITUCIÓN}

Sea como fuere la parte a actualizar, la modificación de la actual Constitución debería someterse a la aprobación por parte de la población española en un referéndum de ratificación. En dicho plebiscito habría una participación mayoritaria de las generaciones que no vivieron el nacimiento de la Carta Magna y que nunca han podido contribuir a una actualización constitucional, y que tienen el derecho a coparticipar en el pacto político-social que representa la Constitución a través de su reforma y puesta al día, porque las normas también envejecen y requieren adaptarse a una realidad en perpetua evolución. Sólo así se podrá afirmar la superioridad de la Constitución, porque de lo contrario una norma anquilosada ni sería de todos ni sería tampoco eficaz (OLIVER ARAUJO, 2010, p. 28).

La Constitución española, al ser una constitución rígida con vocación de permanencia y estabilidad el proceso es más complicado lo que ha dificultado su modernización. A pesar de ello, permanencia no implica inmutabilidad y debe adaptarse a los nuevos momentos sociales para evitar su envejecimiento, anquilosamiento y caducidad ante la nueva realidad social y política, por lo que es necesaria su renovación hacia nuevas ideas y valores (TORRES DEL MORAL, 2004, p. 68). La realidad es dinámica y la reforma constitucional es el instrumento apropiado para amoldar la Constitución a la actualidad sociopolítica que se encuentra en constante cambio.

La última parte y requisito del artículo 168 para aprobar la reforma tramitada es su ratificación en referéndum. Podría resaltarse la contradicción de incluir en un procedimiento de reforma agravado unas elecciones generales y la ratificación popular final, pudiendo llegar a ser redundante la doble consulta.

A pesar de esto, la finalidad es avalar y ratificar la reforma, concediendo al electorado la capacidad de decidir sobre el resultado final de la misma mediante una mayoría simple, para posteriormente proceder a su firma por el Rey y la publicación en el BOE. Adicionalmente a su aceptación o reprobación la reforma constitucional podría detenerse en determinadas las fases del procedimiento, debido a la retirada de las proposiciones y enmiendas, o simplemente a causa de la caducidad del procedimiento.

\section{1 $\mathrm{Y}$ SI EL PROCESO DE REFORMA ES EL FUNDAMENTO DE UNA CONSULTA POPULAR DEL DEBATE SOBRE LA MONARQUÍA?}

¿Podría considerarse factible la realización de un referéndum consultivo anterior al comienzo del proceso de reforma constitucional para conocer la idea y propósitos de los electores? ¿Conllevaría un cambio de rumbo de la política constitucional permitir uno bajo el amparo del artículo 92 de la Constitución? 
El referéndum consultivo avalado por el artículo 92 y el referéndum de ratificación establecido en el artículo 168 no podrían considerarse similares. El referéndum consultivo es propuesto por el Presidente del Gobierno con el respaldo de la mayoría absoluta parlamentaria del Congreso, y lo convoca formalmente el Rey según prevé el artículo 92.2 de la Constitución. Además, la Ley Orgánica 2/1980, de 18 de enero, sobre regulación de las distintas modalidades de referéndum, precisa en su artículo 6 que únicamente la mayoría absoluta es la necesaria para la autorización del referéndum.

Pero en oposición, el referéndum autorizado por el artículo 92 se enfrenta a otros procedimientos de implicación de la ciudadanía que pueden ser impulsados por propia voluntad de la población, como por ejemplo, la iniciativa legislativa popular establecida en el artículo 87.3 de la Constitución y regulada por la Ley Orgánica 3/1984, de 26 de marzo, de la iniciativa legislativa popular, iniciada y desarrollada sin mediación de los representantes políticos. Por ello, dicho referéndum únicamente puede impulsarse con la ratificación de los partidos políticos rechazando de pleno la iniciativa popular como motor de una futura reforma constitucional.

Por tanto, el uso de la consulta popular a que se refiere el artículo 92 para recabar la información necesaria a la ciudadanía acerca de la viabilidad actual de la monarquía no podría aplicarse actualmente a esta situación, ya que la Constitución rechaza esta iniciativa popular mediante el artículo 166 con la finalidad de una reforma constitucional al anteponerlo al proceso parlamentario.

No hay que olvidar que a pesar de ser una iniciativa popular, el referéndum es convocado por decisión de los representantes parlamentarios, bastando la mayoría absoluta del Congreso de los Diputados para su aprobación, por lo que existe una contrariedad en el mecanismo de protección constitucional, oponiéndose al procedimiento planteado en el artículo 168 con el que es necesaria una aprobación por mayoría de dos tercios en ambas cámaras de representación política.

A pesar de ello, debe ser imprescindible la participación de la ciudadanía de acuerdo con el principio de reforma a través de elecciones anticipadas, aunque con la obligatoriedad de que la configuración política mayoritaria, nacida de las elecciones anticipadas a favor de la modificación del texto articulado, conceda a la población la llave de su ratificación mediante referéndum tras una aprobación por supermayoría.

Se entiende que en materias constitucionales sensibles, como el debate sobre la jefatura del Estado en España, el consenso entre las principales fuerzas políticas para su reforma debe ser obligatorio y alcanzarse mediante un acuerdo mayoritario en las Cortes Generales. Por lo que preparar un referéndum consultivo en la primera fase antes de que se haya producido la deliberación y negociación parlamentarias, puede suponer un 
La problemática actual de la Monarquía Española: entre el debate funcional y la discriminación en la sucesión

desequilibrio y separación de las fuerzas políticas al anteponer sus diferencias ideológicas y alterar el sistema de reforma constitucional configurado.

Es necesario remarcar que el referéndum del artículo 92 es exclusivamente consultivo y su celebración no impide la potestad jurídica a los representantes políticos para decidir en qué términos plantear una futura reforma de la Constitución, ya que podría aplicarse que la única función sería conocer las preferencias de los ciudadanos a través de este medio de participación.

De acuerdo con este planteamiento, los diputados siguen siendo los encargados del procedimiento y mantienen la titularidad de poder iniciar y tramitar la reforma, asumiendo el compromiso como propio y logrando los acuerdos que estimen pertinentes, pero este poder se ve altamente condicionado por las decisiones y preferencias que la ciudadanía hubiese expresado por medio de dicho referéndum ${ }^{19}$. Por lo que los resultados se convertirían en el ámbito parlamentario en una formalización de una decisión política tomada previamente.

La realización de una consulta popular sobre el mantenimiento de la monarquía condicionaría enormemente la deliberación y negociación parlamentaria. En el caso de que ganase una apuesta por la república como forma de Estado, los partidarios políticos contarían con el apoyo de una mayoría ciudadana, por lo que las formaciones favorables al mantenimiento de la monarquía poco podrían rebatir a la afirmación de que la soberanía popular reside en el pueblo, asintiendo que la pervivencia de la Corona en España como Jefatura del Estado se decidiría en esa consulta previa, a pesar de ser consultiva.

El desequilibrio institucional y organizativo del proceso de reforma introduciendo un referéndum con carácter preliminar, obligatoriamente ejerce una presión contraproducente en las fuerzas políticas en contra del valor de los pactos. Por ello, es primordial realizarlo de acuerdo con los procedimientos establecidos en la Constitución, ya que si estas formas no se mantuviesen, estaríamos entrando en situaciones de hecho, abiertas a cualquier aventurerismo como el que supuso el llamado Plan Ibarretxe (PECES-BARBA, 2004, p. 28), y que estableció el Tribunal Constitucional en la Sentencia 103/2008, de 11 de septiembre, acerca de la inconstitucionalidad de que se convocase una consulta popular sobre la monarquía mediante el recuro del artículo $92^{20}$.

\footnotetext{
${ }^{19}$ ¿Qué pasaría si el referéndum consultivo sobre la modificación del Título II de la Constitución se convirtiese en la pervivencia o abolición de la monarquía? ¿Cuál sería el enfoque que deberían hacer los diputados en caso de que se desarrollase el trámite en las Cortes en el que se debatiese el mantenimiento de la Corona y las manifestaciones que pudiesen bloquear la consecución de la mayoría parlamentaria necesaria para modificar la Constitución según la declaración realizada por los ciudadanos a través del referéndum?

${ }^{20}$ El Tribunal Constitucional consideró que el referéndum que se intentó celebrar en el País Vasco mediante una ley del Parlamento autonómico para convocar a la ciudadanía a participar en una 
El recurso de inconstitucionalidad presentado tanto por el presidente del Gobierno como por el grupo parlamentario del Partido Popular, considerando el Tribunal la inconstitucionalidad de dicho plebiscito por abarcar un ámbito restringido al proceso de reforma constitucional establecido en el artículo 168, alegando en su Fundamento Jurídico 4 que

El respeto a la Constitución impone que los proyectos de revisión del orden constituido [...] se sustancien abierta y directamente por la vía que la Constitución ha previsto para esos fines. No caben actuaciones por otros cauces ni de las Comunidades Autónomas ni de cualquier órgano del Estado $[\ldots]^{21}$. (ESPAÑA, 2008, online).

Del mismo modo, el Tribunal Constitucional confirmó en pronunciamientos posteriores esta misma línea de actuación a raíz del proceso independentista catalán, en la Sentencia 114/2017, de 17 de octubre, por el que el asunto que se pretendía someter a consulta popular abarcaba de manera íntegra el ámbito reservado al proceso de reforma constitucional establecido en el artículo 168, por el que la Ley del Parlamento de Cataluña 20/2017, de 8 de septiembre fue declarada nula por ser manifiestamente inconstitucional.

\section{CONCLUSIONES}

Los medios de comunicación comentan de manera continuada sobre la desigualdad de género a nivel doméstico, laboral, social, o económico, pero poco se dice sobre la disparidad existente en la Corona, institución tan representativa de España por ser una monarquía parlamentaria, y en la que la sucesión al trono adolece de una igualdad contraria explícita en la Constitución española.

Teniendo en cuenta el momento histórico y el contexto social tras la muerte de Franco, las libertades y avances democráticos que emergieron durante la Transición no se reflejaron en el artículo 57 de la Constitución respecto a la sucesión de la Corona, donde se estableció la preferencia como sucesor al trono a la figura masculina frente a la femenina.

Pero el proceso de reforma previsto en el artículo 168 es muy abrupto y complejo, siendo frecuentes las dudas y posicionamientos a favor de una modificación de dicho

votación sobre "la apertura de un proceso de negociación para alcanzar la paz y la normalización política" era un referéndum encubierto, careciendo de la competencia otorgada al Estado a través del artículo 149.1.32 para permitir la realización de consultas populares a través de este procedimiento y de forma unilateral.

${ }^{21}$ La ley del Parlamento Vasco convocaba en su Exposición de Motivos a los ciudadanos de esa región a concurrir en un referéndum popular sobre "la apertura de un proceso de negociación para alcanzar la paz y la normalización política" y crear "las bases de una nueva relación entre la Comunidad Autónoma del País Vasco y el Estado español".

171 R. Opin. Jur., Fortaleza, ano 19, n. 31, p.154-174, maio/ago. 2021 
La problemática actual de la Monarquía Española: entre el debate funcional y la discriminación en la sucesión

procedimiento, ya que esta vía da a entender su existencia para procurar un consenso entre la mayoría de fuerzas políticas de las Cortes, complicando la reforma en ciertas materias como la cuestión de la Corona o el ámbito de la defensa de los derechos fundamentales y libertades constitucionales, aunque la realidad puede llegar a hacerla imposible.

Opcionalmente, se podría modificar el procedimiento de reforma constitucional por la vía del artículo 168 haciéndolo más flexible en determinados ámbitos, aunque solo sería posible cambiarlo utilizando el propio proceso de dicho artículo, siendo un artificio inconstitucional hacer uso del procedimiento del artículo 167 para alterar el trámite agravado.

A pesar de que los preceptos del artículo 168 no mencionan explícitamente el propio artículo ni su tramitación, la interpretación de regular y modificar la rigidez de algunas partes de la Constitución, resulta de manera obligada el tramitarlo de acuerdo al procedimiento agravado, ya no sólo el Título II sino otras reformas como la estructura territorial del Estado.

La aceptación de esta situación en el que el camino del artículo 168 es prácticamente inviable debido a las grandes confrontaciones entre los representantes políticos para llegar a un pacto, una parte de la ciudadanía considera que sólo un referéndum consultivo podría resolver la adaptación de la igualdad de género en todos los ámbitos constitucionales, más importante si cabe, debido a que la heredera del trono en España es la Princesa Leonor.

Aunque el debate sobre la Corona no finaliza en una actualización de la igualdad de género en la Constitución española, ya que desde el comienzo del régimen constitucional de 1978, existe una parte de la ciudadanía que demanda una consulta sobre la forma de la Jefatura del Estado, por considerar a la monarquía reinante una herencia de la dictadura de Franco.

Si el procedimiento agravado del artículo 168 no estuviese marcado por un itinerario tan complicado, se podría esperar que aludiendo a razones democráticas la tramitación de la consulta sobre la forma de Jefatura de Estado se realizase utilizando el recurso ilícito del referéndum consultivo establecido en el artículo 92, produciendo el estímulo indispensable para evitar la inmovilidad que comprende el procedimiento del artículo 168.

No es extraño apuntar a que si se organizara ese referéndum consultivo y evidenciase de una forma clara el deseo de los españoles por la instauración de la Tercera República, tendría un impacto negativo en el sistema constitucional ya que certificaría el fin del Régimen del 78, tras el que se tendría que elaborar una nueva Constitución con la apertura de una etapa constituyente, en la que el procedimiento de reforma actual no tendría ningún valor. 
El artículo 28 de la Constitución Francesa de 1793 determinaba que "un pueblo siempre tiene el derecho de revisar, de reformar y de cambiar una Constitución. Una generación no puede sujetar a sus leyes a las generaciones futuras”, por lo que siguiendo los trámites constitucionales de la Constitución española vigente es imprescindible dejar atrás las diferencias entre formaciones políticas para poder alcanzar un consenso donde quepa la mayor parte de la ciudadanía.

A pesar de la exigencia del procedimiento de reforma del artículo 168, todavía puede haber un halo de esperanza tomando en consideración los momentos y fases del proceso, y el intento de reforma no debe suponer una sedición constitucional.

\section{REFERÊNCIAS}

ÁlVAREZ CONDE, Enrique; TUR AUSINA, Rosario. Derecho Constitucional. Madrid: Editorial Tecnos, 2018.

ANTEPROYECTO de Constitución. Boletín Oficial de las Cortes, n. 44, 5 de enero de 1978.

BALAGUER CALlEjÓN, María Luisa. Dictamen del Comité Económico y Social Europeo sobre la propuesta de Reglamento del Parlamento europeo y del Consejo, por el que se crea el Instituto Europeo de Igualdad de Género. Revista de Derecho Constitucional Europeo, n. 5, p. 395-398, enero/jun. 2006.

CONSEJO DE ESTADO. Informe sobre modificaciones de la Constitución Española. febrero de 2006.

ESPAÑA. Sentencia 216/1991, de 14 de noviembre. Recurso de amparo 1.844/1988. Contra Sentencia del Tribunal Supremo dictada en recurso de apelación. Vulneración del derecho a la igualdad: acceso de la mujer a las Fuerzas Armadas. Disponible: https://www.boe.es/diario_boe/txt.php?id=BOE-T-1991-30065. Acesso en: 15 nov. 2020.

ESPAÑA. Tribunal Constitucional de España. Sentencia 126/1997, de 3 de julio. (BOE núm. 171, de 18 de julio de 1997). Disponible: http://hj.tribunalconstitucional. es/es-ES/Resolucion/Show/3391. Acesso en: 15 nov. 2020.

ESPAÑA. Consejo de Estado. Informe sobre modificaciones de la Constitución Española. $2006 . \quad$ Disponible: https://www2.uned.es/dpto-derechopolitico/proyecto\%20Informe\%20Consejo\%20Estado.pdf. Acesso en: 15 nov. 2020.

ESPAÑA. Sentencia 103/2008, de 11 de septiembre. (BOE núm. 245, de 10 de octubre de 2008). Disponible: http://hj.tribunalconstitucional.es/HJ/esES/Resolucion/Show/SENTENCIA/2008/103. Acesso en: 15 nov. 2020. 
La problemática actual de la Monarquía Española: entre el debate funcional y la discriminación en la sucesión

FERRANDO BADÍA, Juan. La Monarquía Parlamentaria actual española. Revista de estudios políticos (Nueva Época), n. 13, p. 7-44, 1980.

GARCIA TORRES, J. «Non Sint». La constitución española y las sucesiones nobiliarias "mortis causa»: examen critico de la argumentación constitucional contenida en la Sentencia de la Sala 1a del Tribunal Supremo de 28 de abril de 1989. Revista Española de Derecho Constitucional, v. 10, n. 29, p. 243-289, 1990.

LÓPEZ-ARANGUREN JIMÉNEZ, José Luis. La cruz de la Monarquía española actual. Madrid: Editorial Taurus, 1974.

MÁRQUEZ, Piedad García-Escudero. El procedimiento agravado de reforma de la constitución de 1978. UNED. Revista de Derecho Político, n. 71/72, p. 177-193, enero/agosto 2008.

OLIVER ARAUJO, Joan. Cuatro Reflexiones sobre la Monarquía y la República. Revista de Derecho Político, n. 53, p. 13-24, 2002.

OLIVER ARAUJO, Joan. La reforma constitucional de la Corona (una propuesta radical y diez moderadas). Revista de Derecho Político, n. 77, p. 15-69, enero/abr. 2010.

OLIVER ARAUJO, Joan; CALAFELL FERRÁ, Vicente Juan. De Juan Carlos I a Felipe VI: ¿Algo nuevo bajo el sol?. Corts: Anuario de derecho parlamentario, n. 29, p. 175-224, 2017.

PECES-BARBA, Gregorio. La reforma de la Constitución. Revista Claves de razón práctica, n. 148, p. 26-31, 2004.

PÉREZ SERRANO, Nicolás. Tratado de Derecho Político. [S.l.]: Editorial Civitas, 1984.

QUÍLEZ, Raquel. La constitución continúa discriminando en la línea sucesoria. De infanta a princesa. Disponible:: https://www.elmundo.es/especiales/espana/el-rey/lasucesion.html. Acceso en: 15 nov. 2020.

SÁNCHEZ AGESTA, Luis. Sistema político de la Constitución Española de 1978. Madrid: Editora Nacional, 1984.

TORRES DEL MORAL, Antonio. Estado de Derecho y democracia de partidos. Madrid: Editorial Universitas, 2004.

\section{Como citar este documento:}

MARTÍNEZ CRISTÓBAL, Daniel. La problemática actual de la Monarquía Española: entre el debate funcional y la discriminación en la sucesión. Revista Opinião Jurídica, Fortaleza, v. 19, n. 31, p. 154-174, maio/ago. 2021. 